\title{
First Trimester Spontaneous Abortion
}

National Cancer Institute

\section{Source}

National Cancer Institute. First Trimester Spontaneous Abortion. NCI Thesaurus. Code C128775.

Pregnancy loss at less than 14 weeks 0 days gestation. 